\title{
Film and Neuroradiological
}

\author{
Gerardo Villegas Lopez ${ }^{1 *}$, Jorge Miguel Ibarra Puig ${ }^{2}$, Viridiana Monserrat Pérez CORREA ${ }^{3}$ and \\ Jocelyn Hernandez Avila ${ }^{3}$ \\ ${ }^{1}$ Neuro pediatric radiologist, Sub-director CHOPO medical laboratory, Mexico
}

${ }^{2}$ Neurologist National, Institute of Perinatology Mexico City, Mexico

${ }^{3}$ Médicas Radiologist, CHOPO medical Laboratory, Mexico

*Corresponding author: Gerardo Villegas-López, Pediatric Neuroradiologist, Medical Sub-Director El Chopo laborator, Mexico

\begin{tabular}{|c|c|}
\hline ARTICLE INFO & ABSTRACT \\
\hline Received: October 05,2020 & Citation: Gerardo Villegas L, Jorge Miguel Ibarra P, Viridiana Monserrat PC, Jocelyn \\
\hline Published: 崤October 13, 2020 & $\begin{array}{l}\text { Hernandez A. Film and Neuroradiological. Biomed J Sci \& Tech Res 31(1)-2020. BJSTR. } \\
\text { MS.ID.005055. }\end{array}$ \\
\hline
\end{tabular}

\section{Introduction}

Since the beginning of film, which some authors refer to Paris in 1895 when brothers Louis and Auguste Lumiére presented the first moving images Figure 1. Since then he has undergone several changes in several ways. On the one hand, technology has evolved from its inception with silent cinema to $21^{\text {st }}$ century digital cinema. cine mudo. On the other hand, language has evolved, so different cinematic genres have emerged. It has evolved with society, developing different film movements. Cinema is popular culture, art and spectacle. This article presents some guidelines for using cinema in classic examples of neurological diseases.

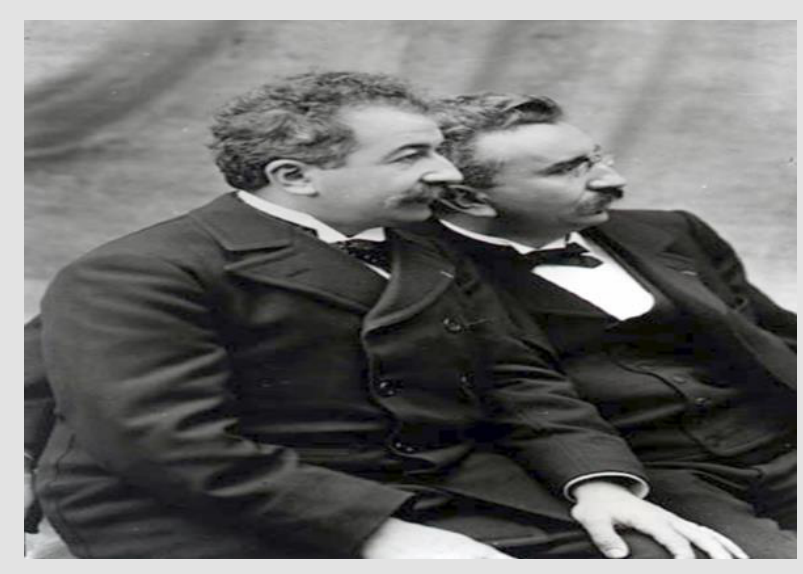

Figure 1: Los hermanos Lumière.
French Film Friends 2011 (Untouchables)

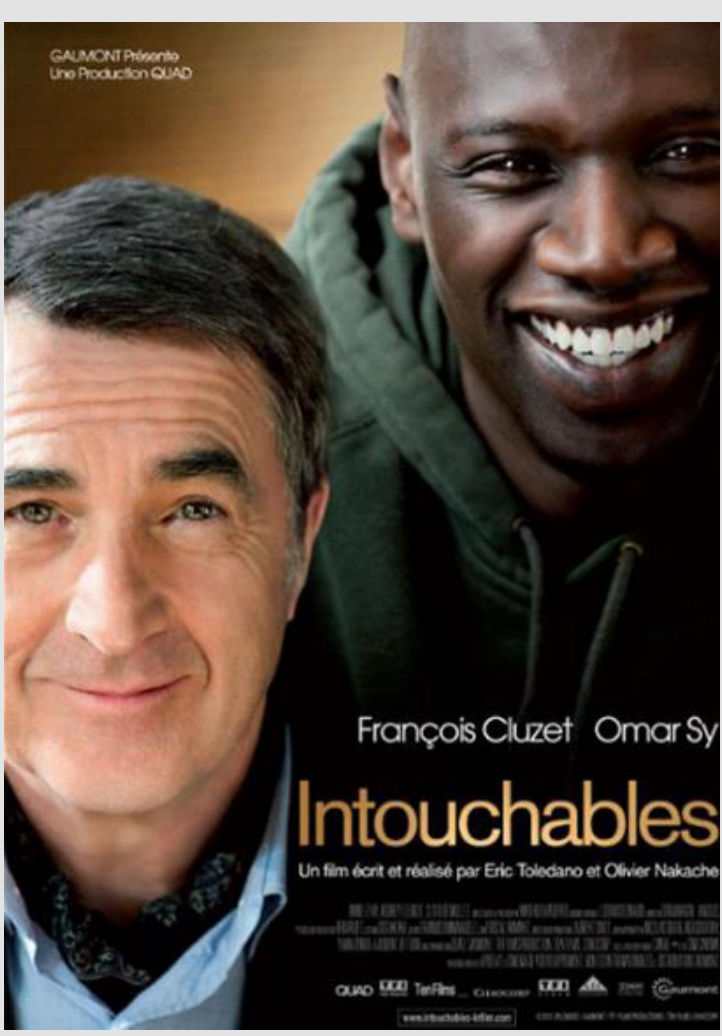

Figure 2: Movie friends. 
It is a drama film directed by Oliver Nakech and Eric Toledano. Story inspired by the life of a rich Count Phillippe Pozzo di Borgo Author of the book "Le Second Soulffle". Two characters, totally opposites are a rich, educated and very intolerant Francoiz Cluzet parapejico since 1993 due to a paragliding accident and his relationship with Omar Sy immigrant from Senegal, with criminal record. The high traumatic medullary section (MS)) can lead to a spectrum of neurological problems, including loss of motor and sensory function, bowel and bladder dysfunction, spasticity, neuropathic pain and autonomic dysreflexia. Signs of suspected spinal injury include limb weakness or paralysis, alterations in trunk or limb sensitivity. Hypophonia (difficulty in language issuance), abdominal breathing, hypotension and paradoxical bradycardia, position in flexion of the paresthesia elbows, pain, deformity in the spine and priapism (Figures 2\&3).

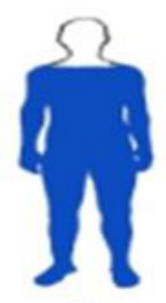

C4

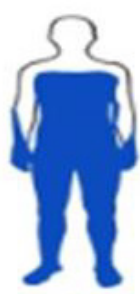

C5

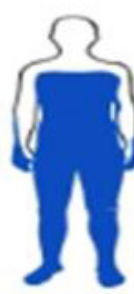

C6

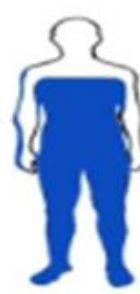

C7

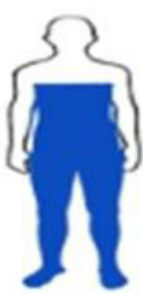

T1

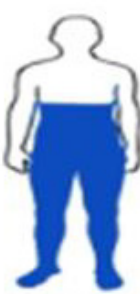

T6

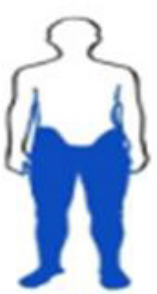

$\mathrm{T} 12$

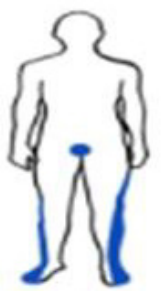

L4

Figure 3: Scheme of sites affected by spinal section in different affected territories (in blue) of the cervical, dorsal and lumbar and sacral region.

\section{Cervical injury C1-C8}

Cervical-level injuries cause paralysis or weakness in both arms and legs (quadriplegia). All regions of the body below the level of the injury or the upper part may be affected Sometimes this type of injury is accompanied by loss of physical sensation, breathing problems, bowel, bladder and sexual dysfunction. This area of the marrow controls signals to the back of the head, neck, shoulders, arms, hands, and diaphragm. Because the neck region is very flexible, it is difficult to stabilize cervical spinal cord injuries.

\section{T1-T12 Chest Injury}

Chest-level injuries are not common because of the protection provided by ribs, except for penetrating gun injuries or firearm projectiles Chest injuries can cause paralysis or weakness of the legs along with loss of physical sensation, bowel, bladder and sexual dysfunction. In most cases, the arms and hands are not affected. This area of the marrow controls signals to some muscles in the back and part of the abdomen.

\section{L1-L5 Lumbar Injury}

Lumbar injuries cause paralysis or weakness of the legs. There may be loss of physical sensation, intestinal, bladder and sexual dysfunction. Typically, the function of the shoulders, arms and hands is not affected. This area of the marrow controls signals to the lower abdomen and back, buttocks, some parts of the external genital organs, and parts of the legs.

\section{S1-S5 Sacred Injury}

Sacrosanct injuries mainly cause loss of bowel and bladder function, as well as sexual dysfunction. These types of injuries can cause weakness or paralysis of the hips and legs. This area of the marrow controls signals to the thighs and lower parts of the legs, feet, and most external genital organs (Figures 4-7).

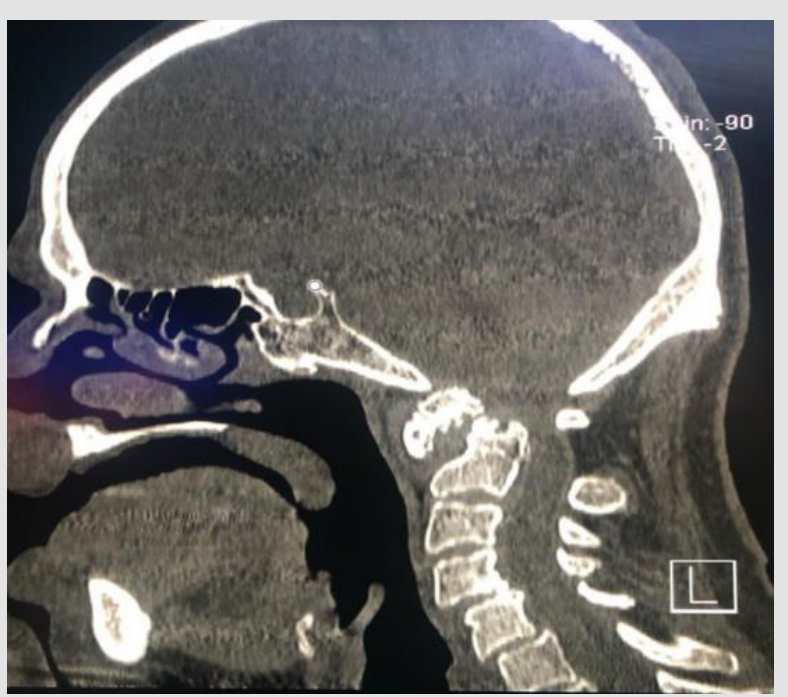

Figure 4: 68-year-old woman, known with vasculitis and rheumatoid arthritis, C1-C2 dislocation fracture with spinal bulb injury, spondylolysis C4-C5 and C5-C6. 


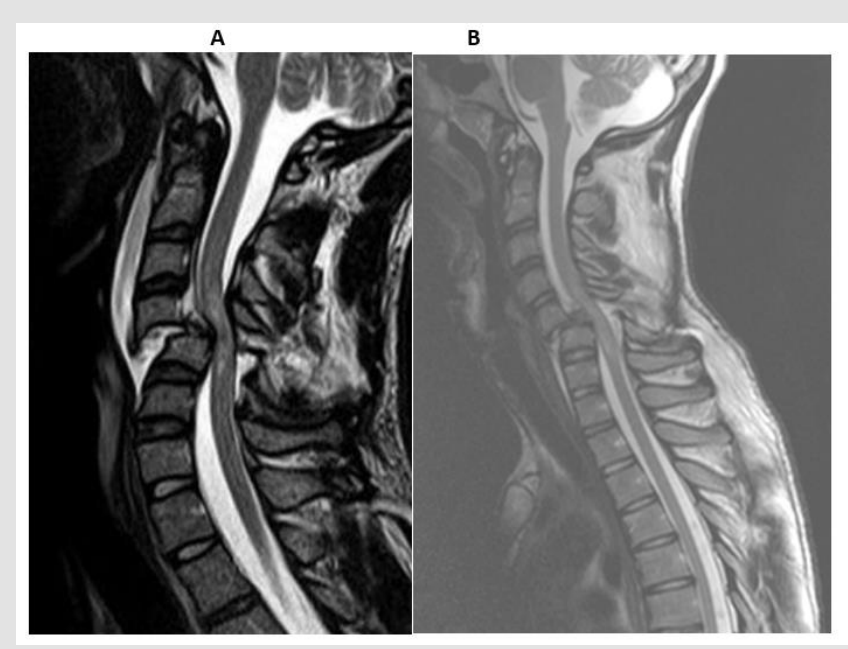

Figure 5:

A.- Traumatic spondylolisthesis $\mathrm{C} 4-\mathrm{C} 5$ with facet fracture C5, spinal section.

B.- 33-year-old woman with car accident 10 hours before, MRI with spinal section C5-C6.

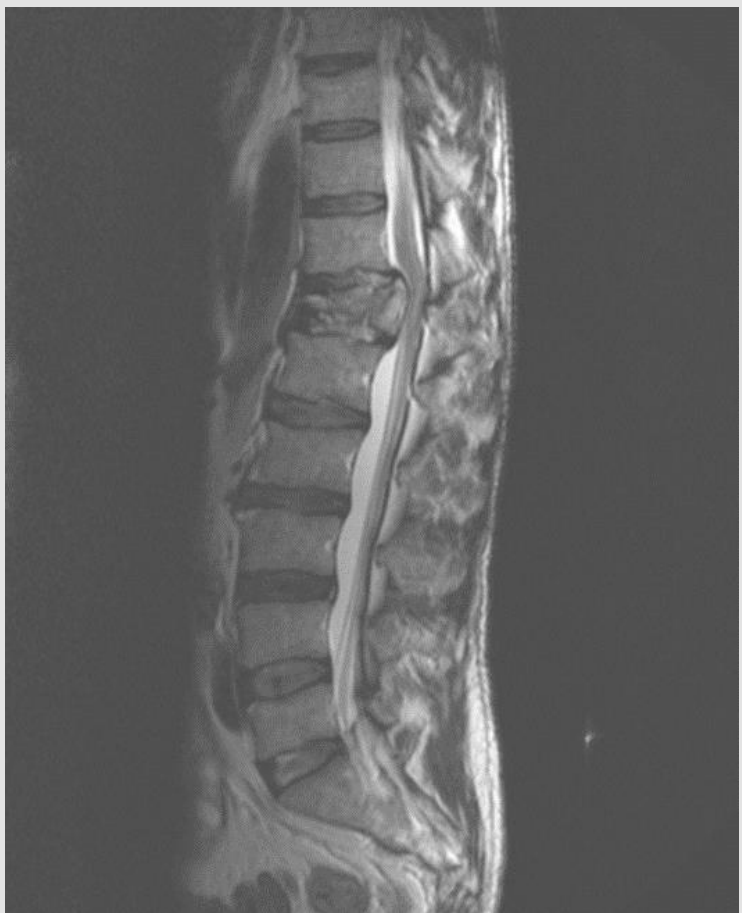

Figure 6: T12 fracture by accident with car overturning, posterior migration of the vertebral body, with spinal section.
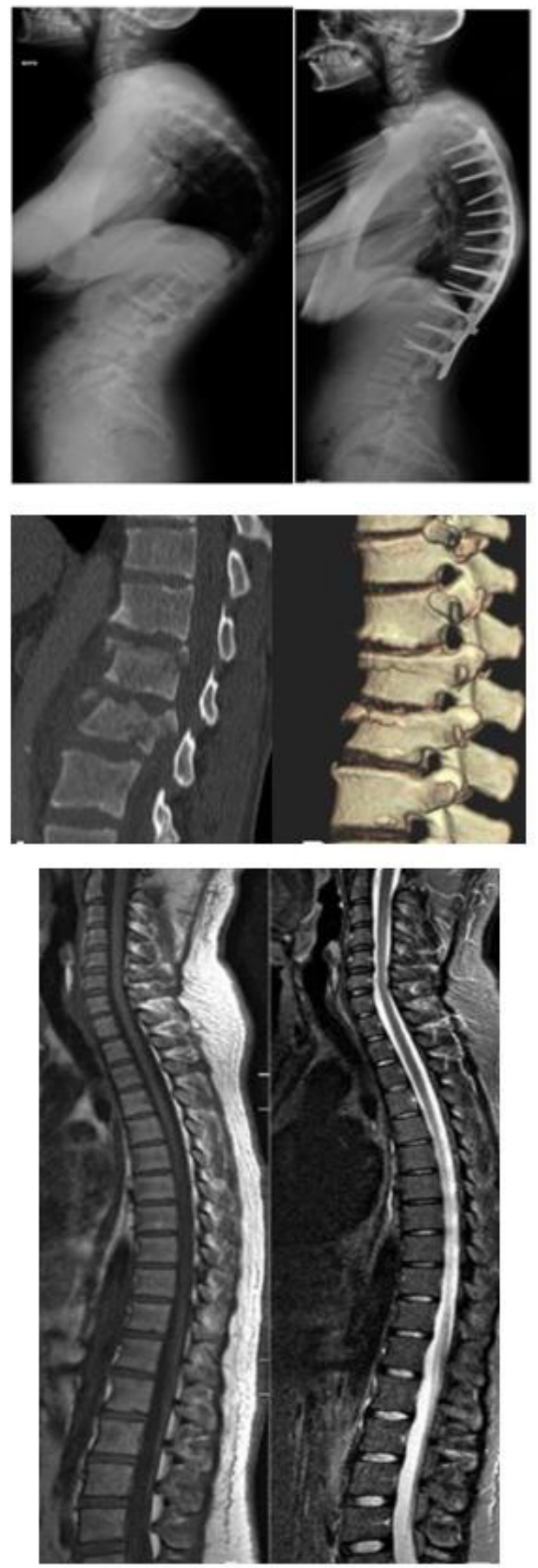

Figure 7: Full spine study utility.

A.- Radiographies.

B.- Tac, with multi-flat and 3D reconstructions.

C.- Magnetic Resonance. 


\section{0/50 Film}

Adam Lerner (Joseph Gordon- Levit) 27-year-old radio journalist along with his artist girlfriend Rachel (Bryce Dallas Howard) and his friend Kyle (Seth Rogen). After experiencing severe back pain, he visits the doctor and discovers that he has neurophyrosarcoma, malignant variety of Schwannoma. In the spine and medical opinion of undergoing chemotherapy treatment. After this Adam, he searches the Internet for information and sees that his chances of survival are $50-50 \%$. Another film in the history of neurofibromatosis refers to the "elephant man". Joseph was born in 1862 with large facial deformities along his nerves, diagnosed as Proteus syndrome and neurofibromatosis. Currently up to 9 types of neurofibromatosis are known, neurofibromatosis type I is included within neurocutaneous syndromes or phacomatosis being the most common of them with an incidence of 1 in 3,200 births Known as Von Recklinghausen's infirmity resulting from a mutation in the gene that encodes the neuro fibrin protein located on chromosome 17. (Figures $8 \& 9$ ) At least 2 of the following criteria should be met by the diagnostic criterion for neurofibromatosis type I (NFI) tener por lo menos 2 de los siguientes criterios (Table 1) (Figures 10-12).
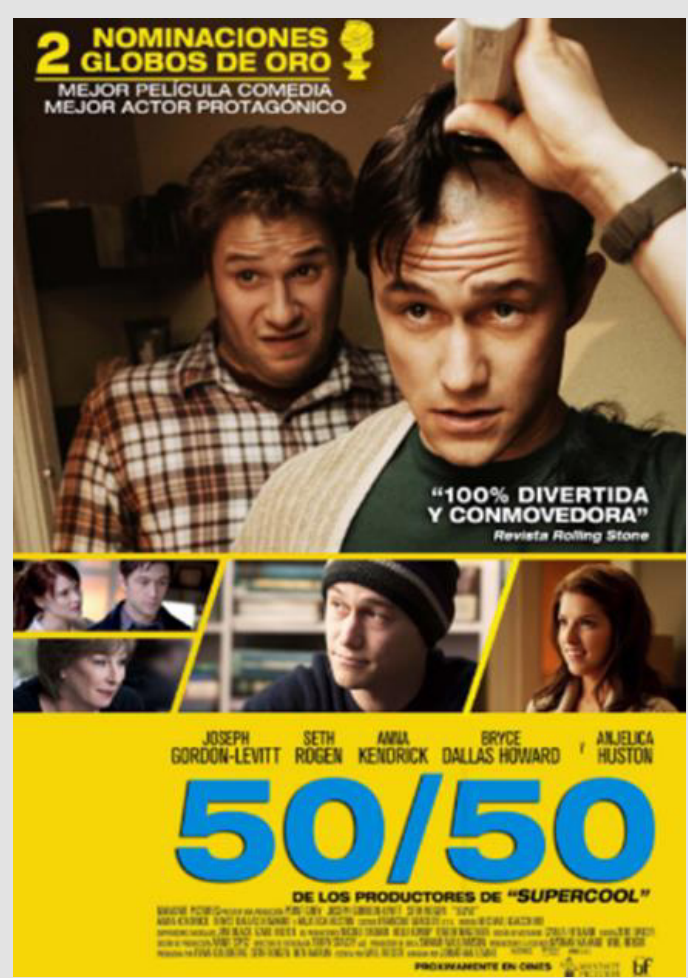

Figure 8: Movie 50/50.

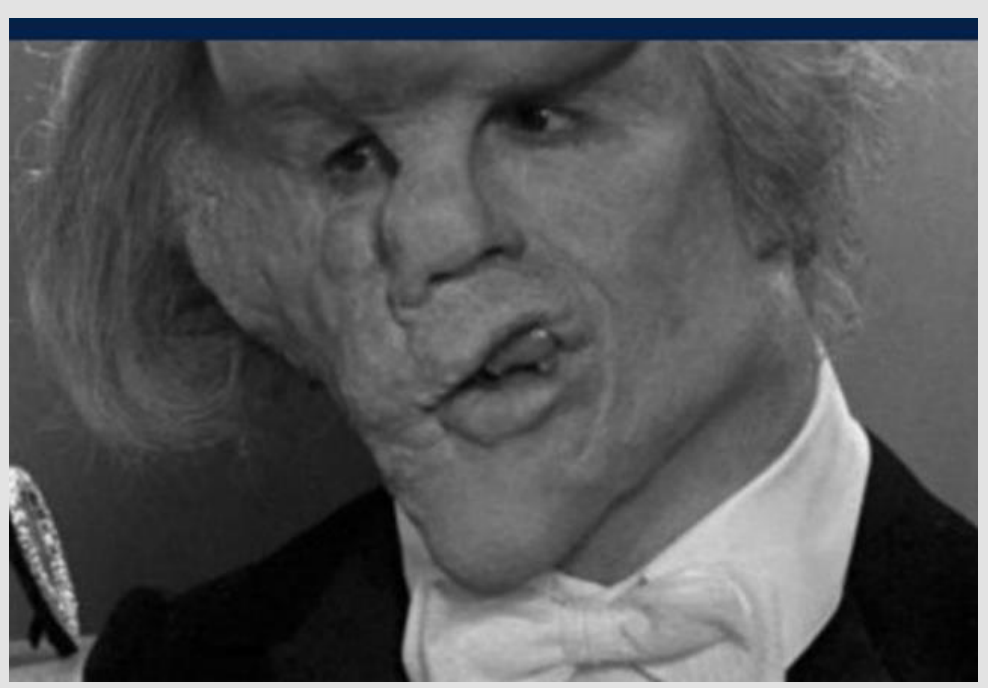

Figure 9: Film the Elephant Man. 


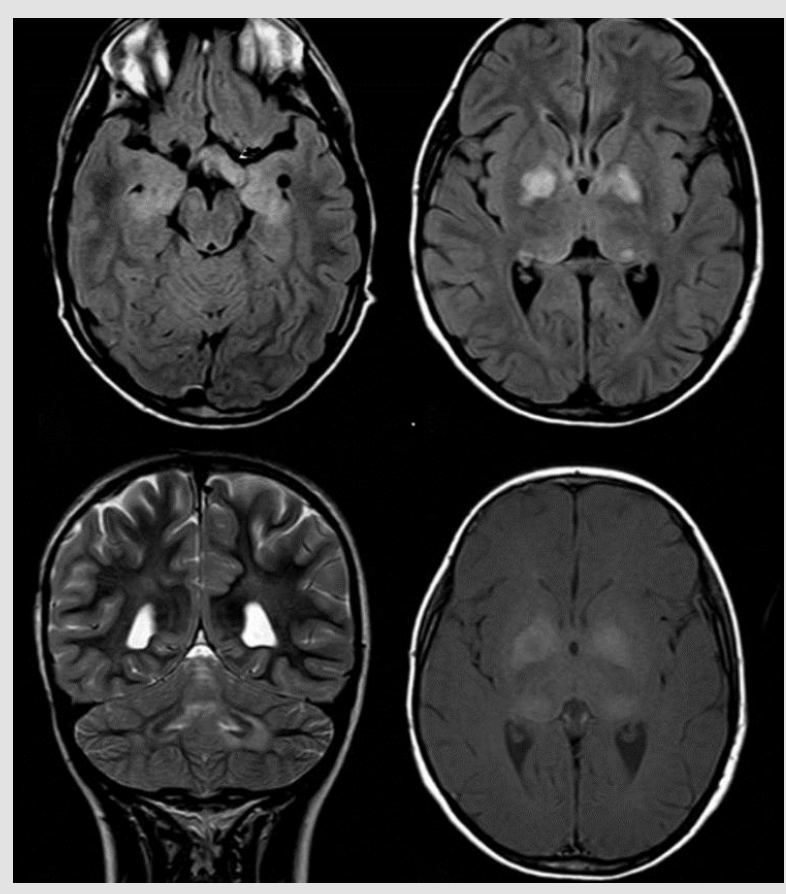

Figure 10: C and B Neurofibromatosis of the visual pathway.

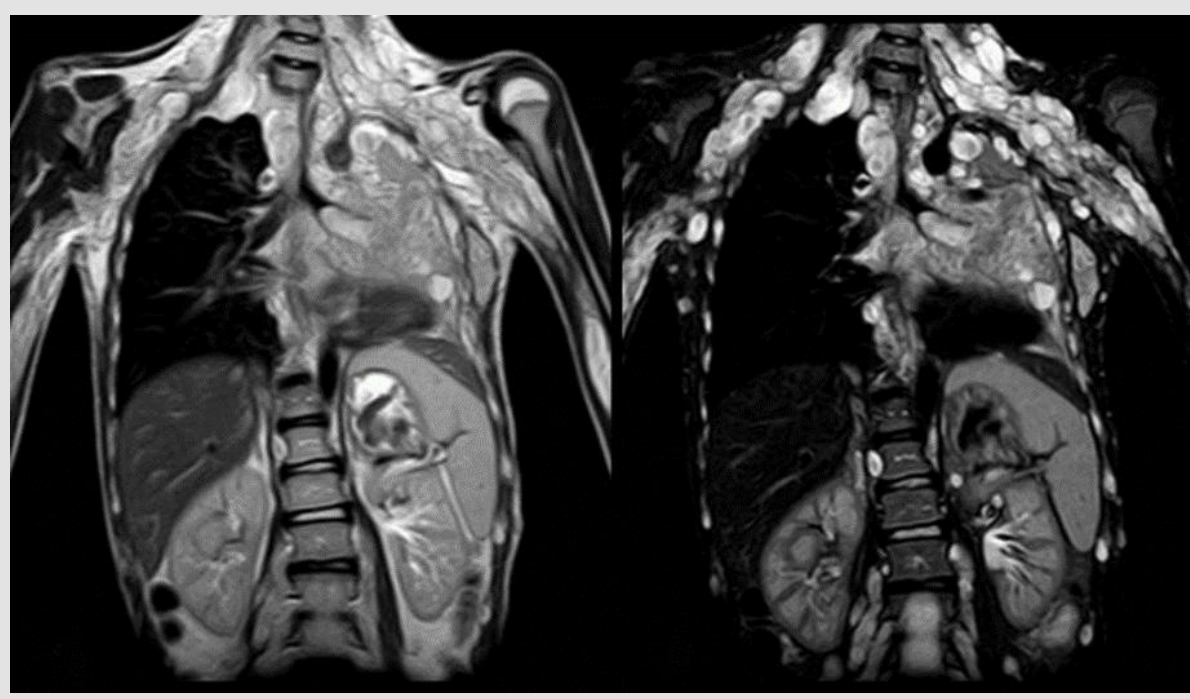

Figure 11: Neurofibromatosis along the brachial plexus with lung and left adrenal gland involvement.

Table 1: Summarized.

\begin{tabular}{|c|c|c|}
\hline At least $\mathbf{6}$ brown stains with milk & Axillary and inguinal ephemeral & Glioma of the visual pathway \\
\hline 2 or more NF & 1 NF Plexiforme & 2 or more Lisch nodules \\
\hline Lytic bone lesions & Dysmorphic scoliosis & First-degree relative with NFI \\
\hline
\end{tabular}




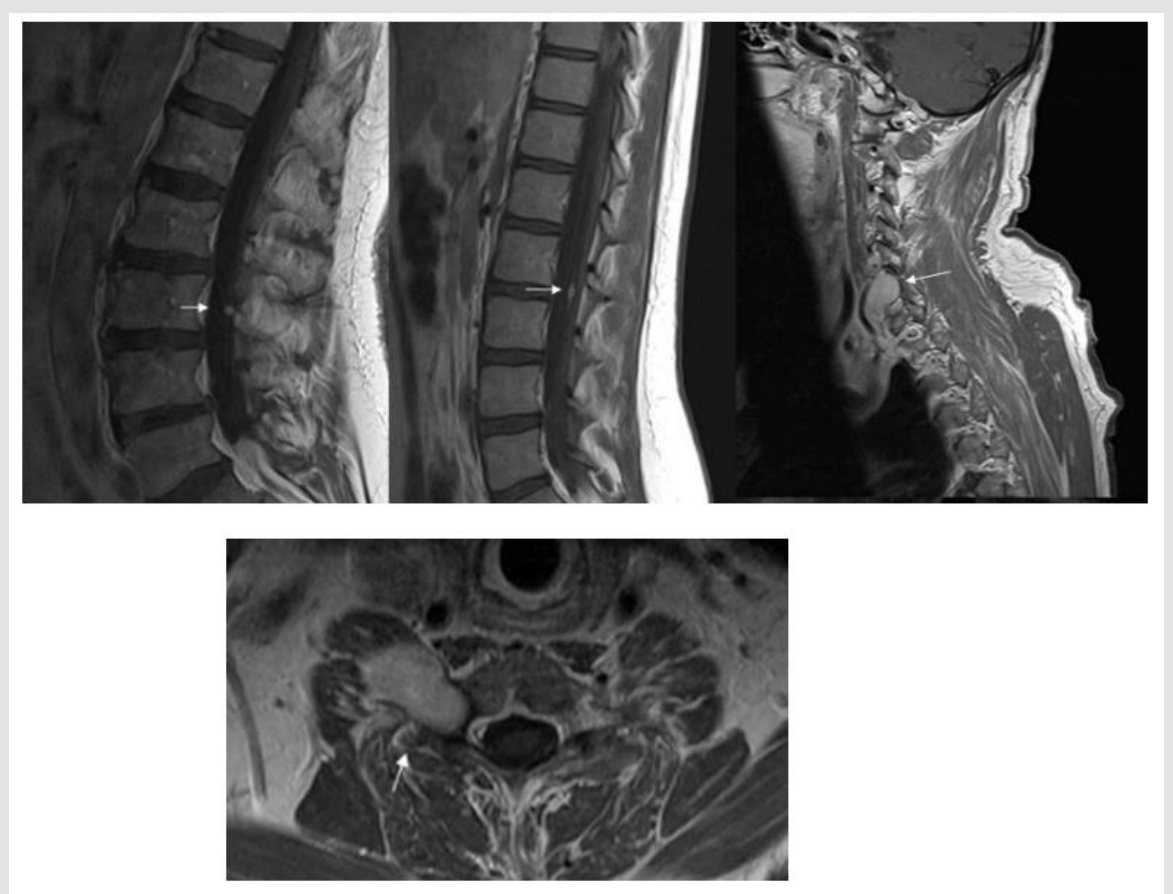

Figure 12: Neurofibromatosis along the brachial plexus with lung and left adrenal gland involvement.

\section{Movie Under the Same Star}

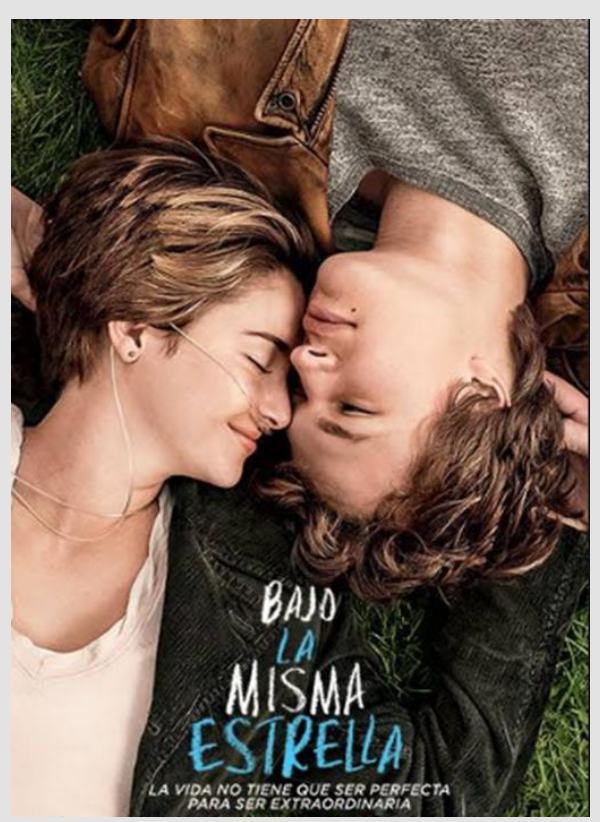

Figure 13: Movie under the same star.

PUS elicle 2014 based on the novel of the same name about difficult life that teens face with neoplasm. Hazel Grace (Shailene woodley) thyroid cancer with late-stage lung metastases Gus Waters (Ansel Elgort) amputated pelvic limb by osteosarcoma. Gus worsens and is taken to ICU where the doctor notifies him that he is close to death, appears his best friend Isaac (Nat wolff) nucleated from both eyes by retinoblastoma (Figure 13). Retinoblastoma is a tumor that accounts for $1 \%$ of all pediatric tumors, the average age of onset at 18 months, and $90 \%$ in children under 5 years of age, as relevant leukocoria singo at more than 50\%. The lesion of chromosome 13. It is presented as a nodular, exophytic retina and endophytic retina mass with invasion of vitreous and anterior bed. Retinoblastoma is presented in computed tomography with retina collection and hyperdense nodular mass and nodular calcifications in more than $90 \%$ magnetic resonance imaging the lesion is isointense to vireo in T1. En T2 is hypointense with reinforcement after injecting gadolinium. It is known several types the most common the onesided, There is bilateral, trilateral and tetra lateral presentation Pellicle the hidden truth and the hidden killer in Aaron Hernandez's mind, both with neurological medical themes, with real-life facts The first stars Will Smith and the second a biography of the football player Aaron Hernandez. Concussion for its original title, 2015 biographical film written and directed by Peter Landsman starring Will Smith as Dr. Bennet Omalu forensic pathologist of Nigeria who investigates chronic brain injury suffered by professional football players chronic traumatic encephalopathy (ETC) (Figures 14-18). 

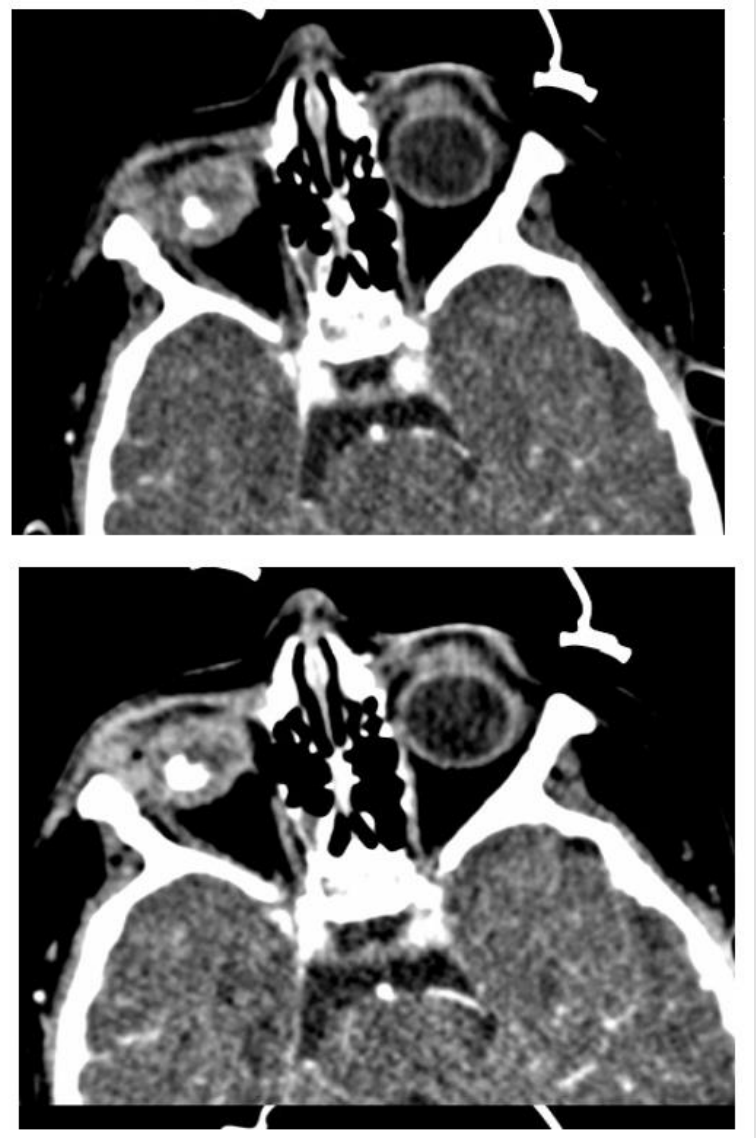

Figure 14: a and b CT scan with unilateral retinoblastoma, unilateral, Leukocoria and retinal calcification.
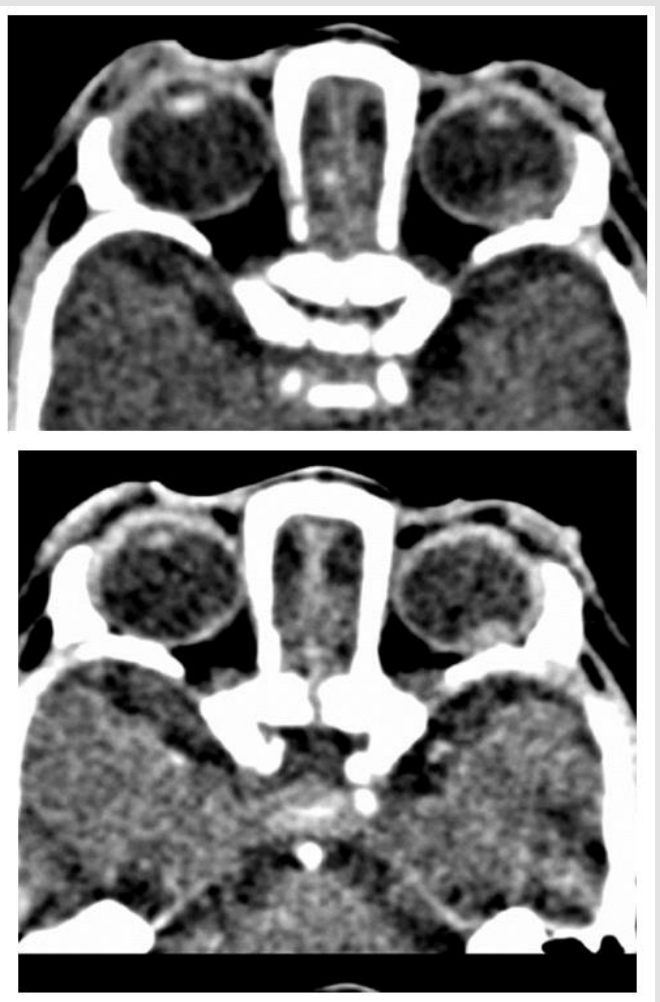

Figure 15: A and B Left Retinoblastoma. 


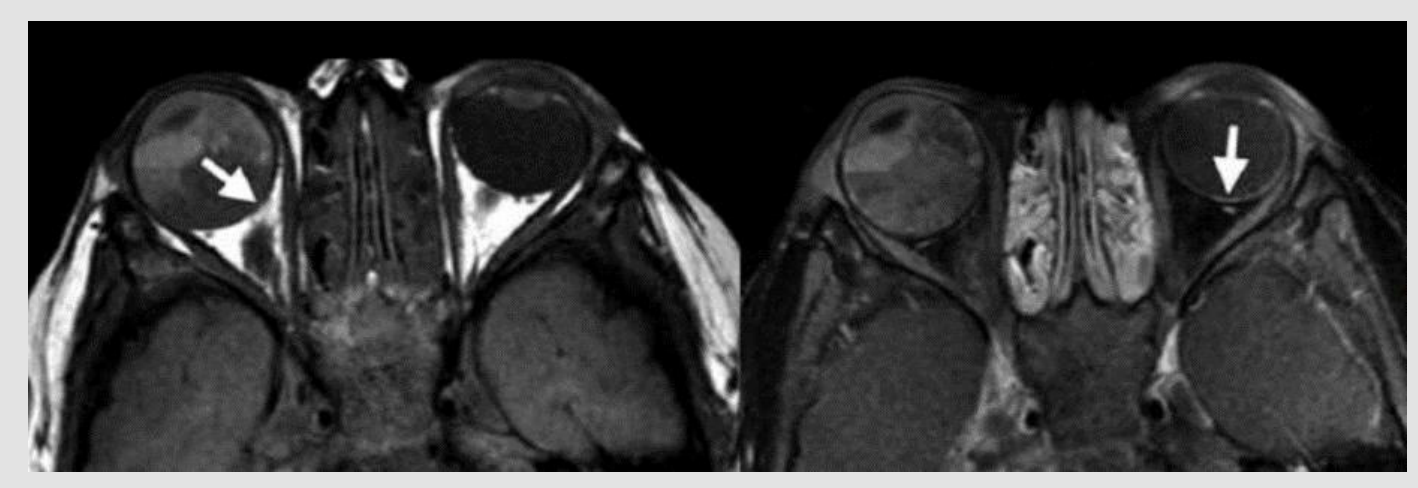

Figure 16: Bilateral retinoblastoma.

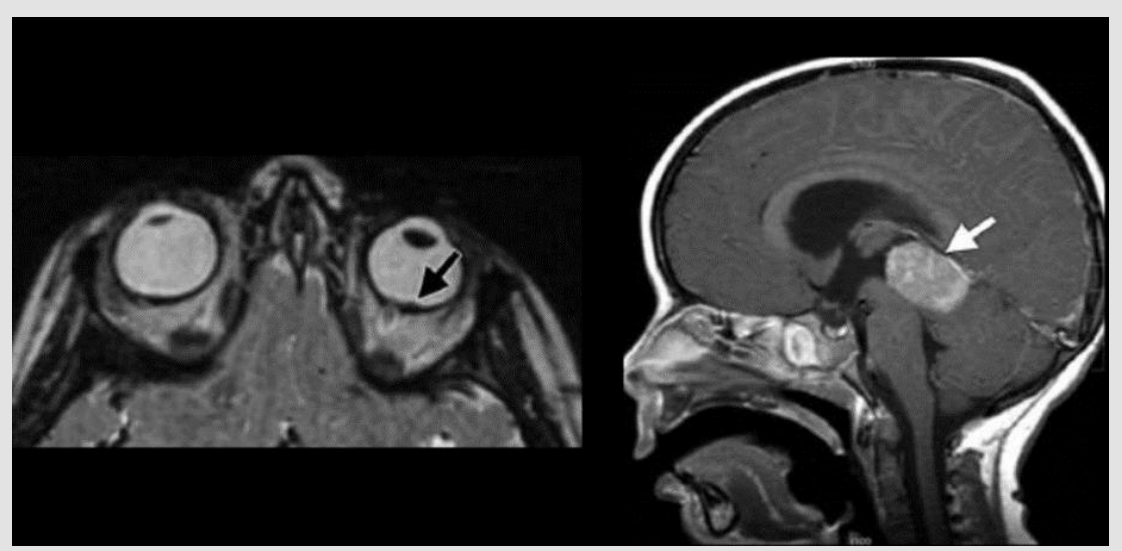

Figure 17: Trilateral retinoblastoma.
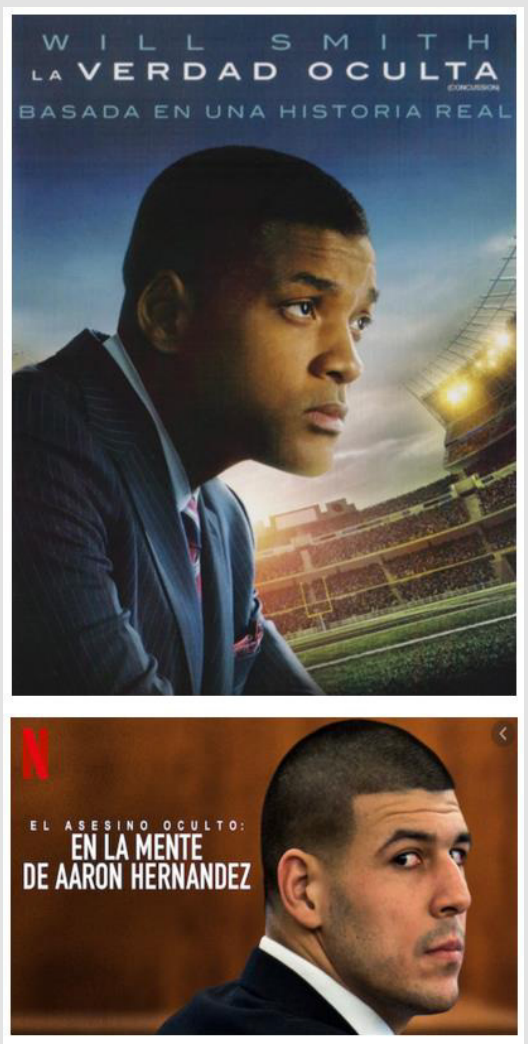

Figure 18. 
Killer inside The Maind of Aaron Hernandez, Aaron Hernandez Professional de Player, New England Football,, Patriots, sentenced to life in prison and exonerated from two other homicides dies hanged in his cell on April 19, 2017 was donated his brain for research finding according to ETC sources, ETC is characterized by abnormal accumulation of hyper phosphoruylated TAU protein in neurons and astorocytes. Harrison Martland quine is first report in the 1928 literature describes "Punch-Drunk" syndrome characterized by tremors, balance disturbances, pyramidal signs and cognitive deficit, similar to Alzheimer's disease (EA) Alzheimer (Muhammad Ali 1942-2016). Connotated boxer was diagnosed with Parkinson's in 1984, noticing his slow diction and persistent fatigue. Since the beginning of the study, 69 cases with emotional lability, memory disturbances, mood swings, pyramidal, extrapyramidal and cerebellar symptoms had been documented, until now only in boxers, in 2005 Omlut reports a professional football player with symptoms of cognitive impairment, mood disorder and Parkinson's, his postmortem study with findings of possible ETC. The findings observed in neuropathology are transferred to the brain image by TAC, MRI and PET-CT, with loss of brain volume, mamilar bodies, thalamus, cavum septum pellucidum, lost ventriculo megalia of the signal and density of locus ceruleus and mesencephalic black substance, these findings are more evident the more advanced the disease by adding wide frontotemporal perivascular spaces (Figures 19-21).

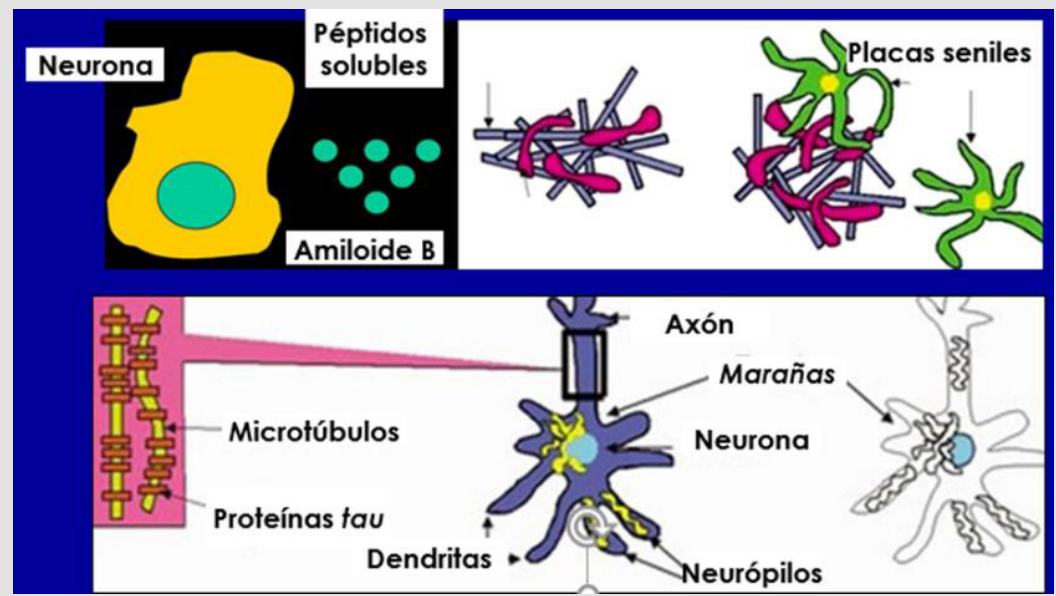

Figure 19.

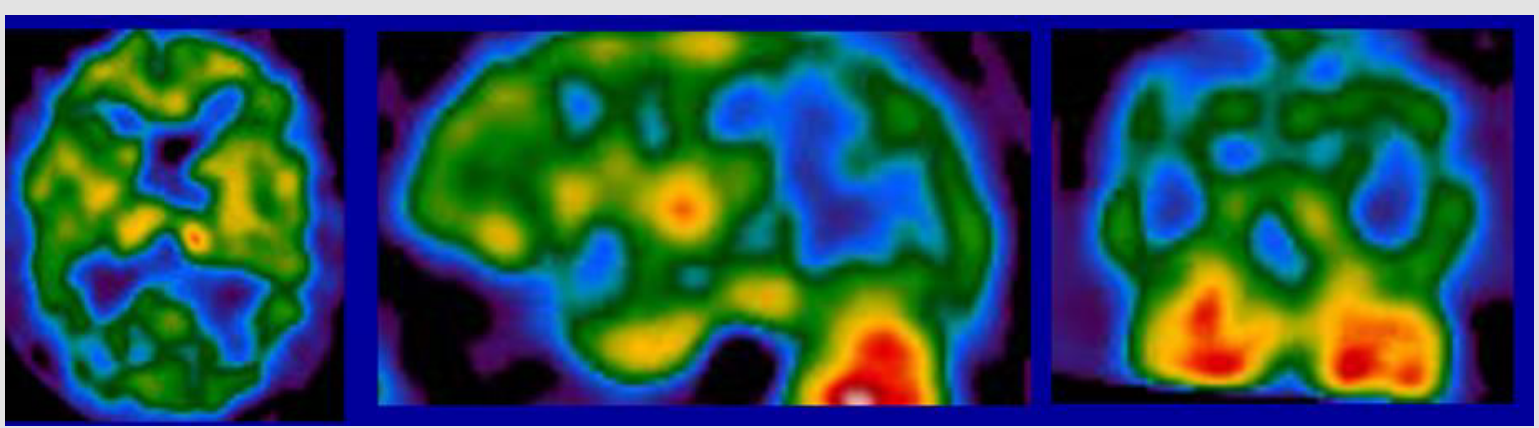

Figure 20.

Microscopically and in PET-CT are p-tau proteins such as neurofibrillary balls and threads in the cerebral cortex around small vessels and in the depth of the sucos, as well as in the frontotemporal cortex, while advanced states there is participation to the hypothalamus, hippocampus and nuclei of the refer Some biological markers used for EA may be useful for ETC as it behaves like similar diseases in different populations. (Figure 19) Neural loss and senial plaques - inflammatory reaction, image like what is observed in ETC. The "plates" are made up of amyloid beta protein tinnitus. Their concentration is very high in dementia, but they are not specific. "Neurofibrilar mares"are filaments of tau protein within axons. (Figure 20) Determines the distribution of a brainbrained radio rater by its deposit neurons and glial cells.

SPECT radiopharmaceuticals emit a single gamma ray. Very useful in patients with dementia, Parkinson's, but indistinguible EA. (Figure 21) EA metabolism of glucose in temporal lobes, parietal and posterior region of the Ingra bun. Sensitivity: $96 \%$, Specificity: $100 \%$, Vascular eminence multiple focal metabolic defects. 
Entermeted Pick glucose metabolism in frontal and temporal lobes (courtesy Dr. Bernardo Boleaga)

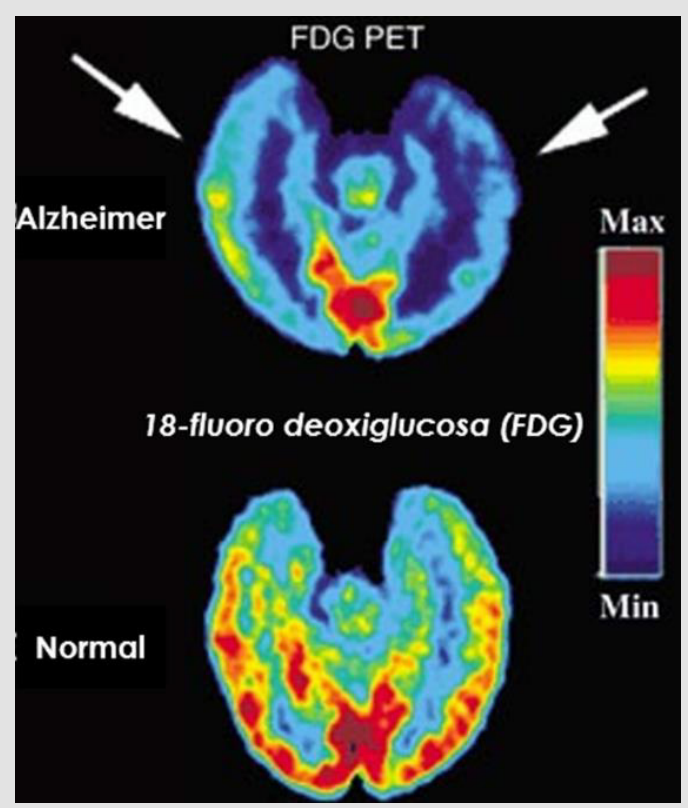

Figure 21 .

\section{Conclusion}

"The image and raw material of life and dreams". José Luis Borges. In cinema and neuroradiology on fusion between internal photography in present time, painting and movement is a total art

\section{ISSN: 2574-1241}

DOI: 10.26717/BJSTR.2020.31.005055

Gerardo Villegas Lopez. Biomed J Sci \& Tech Res

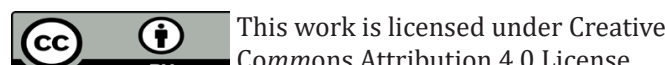

Submission Link: https://biomedres.us/submit-manuscript.php that we can transport ourselves to the patient's past and recent health. We can know the evolution of a disease through some X-rays enjoy cases in which the patient protagonist of our history triumphs in the face of a disease. Many arts become one the art of caring for patients the Radiology is the Radiology (1-12).

\section{References}

1. (2003) N Engl J Med 348: 1215-1222.

2. (2020) Neurologic Imaging. ACR.

3. American College of Radiology. ACR Appropiateness Criteria.

4. www. Hpocampo.org

5. Ana Alanding (2017) Rev. Chil. Neurosurgery 43: 69-73.

6. Carlos Rodríguez-Galindo, Matthew W Willson Pediatric retinoblastoma pediatric oncology Springe NY pp.11-15.

7. Jonathan G, Hobbs JS (2016) Sports-related concussions: diagnosis, complications, and current management strategies Neurosurg Focus (4): E5

8. (2016) Traumatic Encephalopathy and. Current Neurology and Neuroscience Reports 16: 46.

9. Jorge R Barrioa, GWPC Christopher C Gizac, Robert P Fitzsimmonsd (2015) In vivo characterization of chronic traumatic encephalopathy using [F-18] FDDNP PET brain imaging. PNAS 112(16): E2039-E2047.

10. Salgado LP Gavito H, Rojas JR Neuroimagen in Parkinson's.

11. R coll-Fernandeza M, Fragoso, S Escalante, C Corbella-Sala (2008) REV NEUROL 42(12): 760

12. Mayo Clinic. Org Healthy Living medical education research.

13. Tau protein in neurodegenerative diseases, Taupatias Mp Sánchez, V Alvarez-Tallada, journal of neurosciences reading 7057, discharge 978.

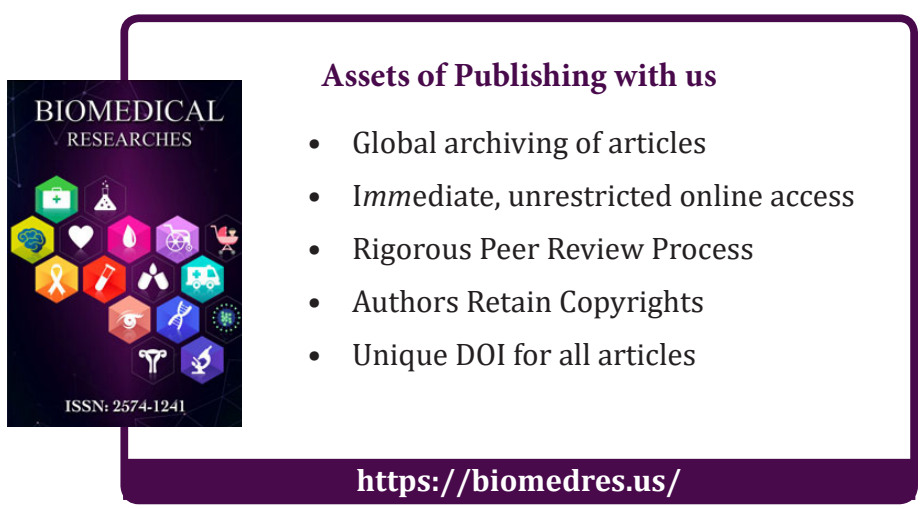

